\title{
Association of serum angiopoietin-2 with malnutrition, inflammation, atherosclerosis and valvular calcification syndrome and outcome in peritoneal dialysis patients: a prospective cohort study
}

Xiaoxiao Yang ${ }^{1,2+}$, He Zhang $^{1,2+}$, Yuanyuan Shi ${ }^{1,2}$, Zanzhe $\mathrm{Yu}^{1,2}$, Hao Yan ${ }^{1,2}$, Zhaohui $\mathrm{Ni}^{1,2}$, Jiaqi Qian ${ }^{1,2}$ and Wei Fang ${ }^{1,2^{*}}$

\begin{abstract}
Background: To examine serum angiopoietin-2 (Angpt-2) in relation to malnutrition, inflammation, atherosclerosis and cardiac valvular calcification, so-called MIAC syndrome and its predictive role in outcomes of peritoneal dialysis (PD) patients.

Methods: A prospective observational study was conducted in 324 chronic PD patients. Biochemical analysis was performed at baseline for serum angiopoietins, albumin and high sensitive C-reactive protein (hs-CRP) and echocardiography was done to detect cardiac valvular calcification. Primary study end points were fatal or nonfatal cardiovascular events and mortality.

Results: The median of serum Angpt-2 levels was $5.44 \mathrm{ng} / \mathrm{mL}$ (interquartile range, 3.41-7.85). Across the three tertiles of serum Angpt-2, a significant trend effect was observed for body mass index, normalized protein catabolic rate, calcium $\times$ phosphorus product, hs-CRP, brain natriuretic peptide, lower-density lipoprotein cholesterol, left ventricular ejection fraction, total weekly urea clearance and residual renal function (all $p<0.05$ ). Serum Angpt-2 showed a significant increase across the four groups of patients with increasing components of MIAC syndrome $(p<0.001)$. There were 77 deaths and 57 cardiovascular events. High serum Angpt-2 was an independent predictor of fatal and nonfatal cardiovascular events in PD patients $(p=0.02)$, however serum Angpt-2 was not an independent predictor of all-cause mortality $(p=0.3)$.
\end{abstract}

Conclusions: Serum Angpt-2 showed close association with valvular calcification, atherosclerosis, inflammation and malnutrition, having significant independent prognostic value and is useful for cardiovascular event stratification in chronic PD patients. Angpt-2 might be a potential mediator of increased cardiovascular risk in patients undergoing PD treatment.

Keywords: Angiopoietin-2, Atherosclerosis, Calcification, Inflammation, Malnutrition, Peritoneal dialysis

\footnotetext{
${ }^{*}$ Correspondence: fangwei_sh@126.com

†Xiaoxiao Yang and He Zhang contributed equally to this work

${ }^{1}$ Department of Nephrology, Renji Hospital, School of Medicine, Shanghai Jiao Tong University, No. 160, Pujian Road, Pudong District,

Shanghai 200127, People's Republic of China

Full list of author information is available at the end of the article
} 


\section{Background}

Overall mortality rates among end-stage renal disease (ESRD) patients have consistently declined over the last 15 years, but dialysis patients continue to have substantially higher mortality compared to the general population and nearly half of the deaths are accounted for by cardiovascular causes [1]. It is widely recognized that dialysis patients are at higher risk of developing accelerated cardiovascular diseases (CVD), resulted from a clustering of both traditional and non-traditional risk factors. It has been reported that an elevation of either C-reactive protein (CRP) or interleukin-6 (IL-6), as a biomarker of systemic inflammation, was strongly associated with CVD in peritoneal dialysis (PD) patients [2], as well as risk factors of both all-cause and cardiovascular mortality [3-5]. Malnutrition assessed either by subjective global assessment (SGA) [6] or by serum albumin [7] in PD patients is associated with a statistically significant increase in mortality. There is a tight link among malnutrition, inflammation and atherosclerosis (MIA syndrome) in chronic renal failure patients [8] as well as dialysis patients [9]. It had been reported that more than $80 \%$ of young patients on dialysis had extensive coronary artery calcification correlated with the duration of dialysis [10]. Cardiac valvular calcification (VC) is a powerful predictor for mortality and cardiovascular deaths in long-term dialysis patients [11]. Previous study demonstrated a strong association of inflammation and malnutrition with cardiac $\mathrm{VC}$, similar to that of atherosclerosis, which was together called as MIAC syndrome [12].

Angiopoietin-1 (Angpt-1) and angiopoietin-2 (Angpt2) are ligands of the Tie- 2 receptor, a family of growth factors specific for the vascular endothelium [13-15]. Angpt-1-mediated Tie-2 activation is required to maintain quiescent endothelium, while Angpt-2 destabilizes quiescent endothelium. In addition to angiogenesis, Fiedler et al. [16, 17] had found that Angpt-2 might play an effective role in regulating endothelial cell inflammatory response, thereby exerting a permissive role for the activities of pro-inflammatory cytokines. Circulating Angpt-2 level was increased in chronic kidney disease (CKD) patients [18] as well as in patients undergoing dialysis treatment and individual Angpt-2 levels significantly decreased within 3 months after kidney transplantation [19]. One explanation for increasing Angpt-2 level in CKD patients with or without dialysis treatment might be the high inflammatory status among these patients, furthermore increased Angpt-2 expression has been observed on stimulation with high glucose and tumor necrosis factor- $\alpha$ levels, both frequently observed in dialysis patients $[16,20]$. Angpt- 2 might be a mediator (and thus a marker) that accounts for accelerated atherosclerosis in dialysis patients $[19,21]$. However, high risk of the cardiovascular event as well as cardiovascular mortality in PD patients is still an unsolved question.

With this background, we examined serum Angpt-2 in relation to cardiac valvular calcification, atherosclerosis, inflammation and malnutrition, so-called MIAC syndrome in chronic PD patients, furthermore the predictive role of increased serum Angpt-2 and the MIAC syndrome in the clinical outcomes of chronic PD patients.

\section{Materials and methods \\ Study design}

This was a prospective observational study based on a single center in China. Study participants were recruited between January 2014 and April 2015 and prospectively followed up to the end of the study (31 January 2018). All procedures followed in this study were in accordance with the ethical standards of the responsible committee on human experimentation (institutional and national) and with the Helsinki Declaration of 1975. The study protocol was approved by the Human Research Ethics Committee of Renji Hospital, School of Medicine, Shanghai Jiao Tong University. All participants gave their written informed consent.

\section{Study participants}

Patients were eligible for study entry if they had been maintained stably on PD treatment. Exclusion criteria included patients developing acute coronary syndrome, acute heart failure, peritonitis, exit-site infection, or other infective complications, or with underlying active malignancy, chronic liver disease, systemic lupus erythematosus requiring immunosuppression, systemic vasculitis, chronic rheumatic heart disease and congenital heart disease; presence of systemic inflammatory disease; patients who refused to give consent; or patients with incomplete data. Based on inclusion and exclusion criteria, 324 PD patients were recruited in our study, representing $72 \%$ of the total PD population in our center. All patients were dialyzed using conventional lactate-buffered glucosebased PD solutions (Dianeal ${ }^{\circledR}$, Baxter, China).

\section{Clinical and demographic data collection}

The following demographic characteristics were collected at study baseline: age, gender, underlying cause of ESRD, duration on dialysis, height, weight, presence of diabetes mellitus (DM) and atherosclerotic vascular disease (AVD). AVD was defined as the presence of ischaemic heart disease, history of angina, previous myocardial infarction, coronary artery bypass surgery or stenting, cerebrovascular event, transient ischaemic attack or peripheral vascular disease with or without amputation. DM was defined either as a comorbid disease or as the etiology of ESRD. Body mass index was calculated as 
body weight in kilograms divided by height in meters squared.

\section{Angiopoietin-2 and biochemical parameters assay}

At the time of enrollment, fasting venous blood of each patient was collected for the measurement of serum Angpt-1, Angpt-2, soluble Tie-2 (sTie-2). Serum Angpt1, Angpt-2 and sTie-2 were determined using enzyme linked immunosorbent assay (ELISA) kit (R\&D Systems Inc, Minneapolis, MN, USA). All samples were run simultaneously and in duplicate to avoid intra- and inter-assay variations. The following laboratory parameters were also measured: high sensitive C-reactive protein (hs-CRP), serum albumin, hemoglobin, calcium, phosphorus, intact parathyroid hormone (iPTH), lipid profile (which include total cholesterol, lower-density lipoprotein (LDL) cholesterol, high-density lipoprotein (HDL) cholesterol and triglyceride) and brain natriuretic peptide (BNP). hs-CRP was measured using the Tina-quant CRP (Latex) ultrasensitive assay (D \& P modular analyser, Roche Diagnostics GmbH, Mannheim, Germany). Serum albumin was measured using the bromcresol purple method, while total holesterol and triglyceride, using enzymatic assay on the Hitachi 911 analyzer (Roche Diagnostics GmbH). BNP was measured using a fluorescence immunoassay with the Triage BNP Test (Biosite, San Diego, CA). iPTH was determined by chemiluminescence immunoassay on the Immulite analyser (Diagnostic Products Corp., Los Angeles, CA).

\section{Indices of dialysis adequacy}

Patients were asked to collect 24-h urine and dialysate to measure urea and creatinine concentrations. Adequacy of dialysis was determined by measuring total weekly urea clearance $(\mathrm{Kt} / \mathrm{V})$ and creatinine clearance $(\mathrm{Ccr})$ using standard methods [22]. Weekly Ccr was normalized to $1.73 \mathrm{~m}^{2}$ of body surface area. Contribution of urea clearance by peritoneal dialysis was estimated separately. Residual renal function was calculated as an average of 24-h urine urea and creatinine clearance [23]. Urea nitrogen and creatinine concentrations were determined using enzymatic assay on the Hitachi 911 analyzer (Roche Diagnostics $\mathrm{GmbH}$ ). Normalized protein catabolic rate (nPCR) was calculated by the methods described by Randerson, Chapman, and Farrell and normalized to standard body weight (total body water/0.58) [24]. Total body water $(\mathrm{V})$ was determined by Watson and Batt's formula [25].

\section{Echocardiography}

Two-dimensional echocardiography was performed using a Vingmed GE System Sonographic machine. All echocardiographs were performed according to the recommendations of the American Society of Echocardiography [26] and were analyzed by a single experienced cardiac sonographer. Cardiac VC was defined as bright echoes on one or more cusps of more than $1 \mathrm{~mm}$ in either mitral or aortic valves or both. Sensitivity and specificity for echocardiographic detection of calcium in both the mitral and the aortic valves have been reported to be $76 \%$ and $89-94 \%$, respectively [27]. Left ventricular (LV) mass index was calculated using the modified American Society of Echocardiography cube formula proposed by Devereux et al. [28] and indexed by body surface area.

\section{Follow-up}

All patients were followed up prospectively from the enrollment of the study until death, cessation of PD, transfer to other centers, or to the end of the study (31 January 2018). The outcomes evaluated were death from all causes and fatal or nonfatal cardiovascular events. For patients who developed multiple cardiovascular events, survival analysis was limited to the first event. Cardiovascular event included acute myocardial ischemic event, sustained atrial or ventricular arrhythmia, stroke, peripheral vascular disease and sudden death defined and diagnosed clinically as unexpected natural death within $1 \mathrm{~h}$ from symptom onset and without a prior condition that would appear fatal $[29,30]$. Acute myocardial ischemia was diagnosed by the attending physician based on the presence of symptoms and serial electro- cardiographic and cardiac enzyme changes in accordance with World Health Organization criteria.

\section{Statistical analysis}

Continuous data were expressed as mean $\pm S D$ or median (interquartile range) depending on the distribution of data. Patients were stratified by tertiles of serum Angpt-2 concentration. Comparisons across the tertiles were performed using one-way analysis of variance (ANOVA), Kruskal-Wallis test or $\chi^{2}$ test, when appropriate. Cumulative survival curves were generated using the Kaplan-Meier method and log-rank test. In the view of the skewed distribution, serum Angpt-1, Angpt-2, sTie2, Angpt-1/Angpt-2 ratio were $\log _{10}$-transformed before performing comparison among different groups of MIAC syndrome and entering into the Cox analysis. The Cox proportional hazards model was used to estimate the relative risks of all-cause mortality and fatal and nonfatal cardiovascular events for different variables. Basic demographic characteristics and components of MIAC syndrome as well as factors with $p<0.05$ on univariate Cox analysis for all-cause and fatal and non-fatal cardiovascular events were further entering into the multivariate Cox regression analysis. We plotted scaled schoenfeld residuals versus time for all variables and computed 
their correlation against time to confirm that all variables considered in the Cox regression analysis met the assumptions of proportional hazards. A $p$-value of $<0.05$ was considered to be statistically significant. Statistical analysis was performed using SPSS software, version 11.0 (SPSS, Inc., Chicago, IL).

\section{Results}

\section{Characteristics of the cohort}

A total of 324 patients were enrolled, which consisted of $166(51 \%)$ males with a mean age of $57.4 \pm 14.1$ years and median PD duration of 31.5 (12.4-57.1) months. The causes of ESRD were chronic glomerulonephritis in 100 patients (30.8\%), diabetic nephropathy in 42 patients (13.0\%), hypertensive nephrosclerosis in 12 patients (3.7\%), obstructive uropathy in 4 patients $(1.2 \%)$, polycystic kidney disease in 9 patients (2.8\%), tubulointerstitial nephritis in 10 patients (3.1\%), others 20 patients (6.2\%). Underlying renal diagnosis was unknown in 127 patients (39.2\%). The detail baseline characteristics of participants were summarized in Table 1.

\section{Parameters between different tertiles of circulating angiopoietin-2 level}

The median serum Angpt-1, Angpt-2, sTie-2 level of the cohort was $42.0(28.30-64.82) \mathrm{ng} / \mathrm{mL}, 5.44$ (3.41$7.85) \mathrm{ng} / \mathrm{mL}$ and 20.10 (15.26-25.42) ng/mL, respectively. Patients were stratified into three tertiles according to the serum Angpt-2 concentration, namely those with serum Angpt- $\leq 3.94 \mathrm{ng} / \mathrm{mL}$ (lower tertile), those with serum

Table 1 Baseline characteristics of the study population

\begin{tabular}{|c|c|}
\hline Variables & Total $(n=324)$ \\
\hline Age (year) & $57.4 \pm 14.1$ \\
\hline Male gender (n [\%]) & $166(51 \%)$ \\
\hline Dialysis duration (month) & $31.5(12.4-57.1)$ \\
\hline Body mass index $\left(\mathrm{kg} / \mathrm{m}^{2}\right)$ & $23.2 \pm 3.9$ \\
\hline Diabetes mellitus (n [\%]) & $84(25.9 \%)$ \\
\hline Background AVD (n [\%]) & $99(30.6 \%)$ \\
\hline Background VC (n [\%]) & $67(22.3 \%)$ \\
\hline Serum albumin (g/L) & $37.0 \pm 4.6$ \\
\hline Hemoglobin (g/L) & $107.4 \pm 17.0$ \\
\hline hs-CRP (mg/L) & $2.5(0.9-6.6)$ \\
\hline $\mathrm{Ca} \times \mathrm{P}\left(\mathrm{mg}^{2} / \mathrm{dL}^{2}\right)$ & $58.0 \pm 18.8$ \\
\hline iPTH (pg/L) & $282.0(134.0-591.0)$ \\
\hline Total weekly urine clearance & $1.94 \pm 0.37$ \\
\hline Total weekly creatinine clearance $\left(\mathrm{L} /\right.$ week $\left./ 1.73 \mathrm{~m}^{2}\right)$ & $62.0 \pm 18.26$ \\
\hline Residual renal function (mL/min) & $0.92(0-2.88)$ \\
\hline
\end{tabular}

Calcium $\times$ phosphorus product in $\mathrm{mg}^{2} / \mathrm{dL}^{2}$ to $\mathrm{mmol}^{2} / \mathrm{L}^{2}, \times 0.0806$

$A V D$ atherosclerotic vascular disease, $V C$ valvular calcification, $h s-C R P$ high sensitive $\mathrm{C}$-reactive protein, $i$ PTH intact parathyroid hormone, $\mathrm{Ca} \times \mathrm{P}$ calcium $\times$ phosphorus product
Angpt-2 between 3.94 and $7.03 \mathrm{ng} / \mathrm{mL}$ (middle tertile) and those with serum Angpt- $2 \geq 7.03 \mathrm{ng} / \mathrm{mL}$ (upper tertile). The clinical and demographic characteristics of patients across the three tertiles of serum Angpt-2 were detailed in Table 2. A trend effect was observed across the three tertiles of increasing serum Angpt-2 concentration for body mass index, nPCR, calcium $\times$ phosphorus product, hs-CRP, BNP, LDL cholesterol, LV ejection fraction, total weekly urine clearance, total weekly creatinine clearance and residual renal function (all $p<0.05$ ). No significant difference was observed in the serum albumin across the three tertiles of increasing serum Angpt-2 concentration (all $p>0.05$ ).

\section{Correlation of circulating angiopoietin-2 level with MIAC syndrome}

Serum Angpt-2 differed significantly among the four groups of patients stratified on the basis of the presence or absence of AVD and valvular calcification (overall; $p=0.003)$. Patients with neither AVD nor valvular calcification had the lowest serum $\log _{10}$ Angpt-2 while those with both AVD and valvular calcification had higher serum Angpt-2 $(p=0.05)$. Serum Angpt-2 did not differ significantly between patients with either valvular calcification or AVD ( $p>0.05$, Additional file 1: Figure S1A). Patients were also stratified into four groups on the basis of the presence or absence of inflammation and malnutrition. Inflammation was defined as those with hs-CRP $\geq 5 \mathrm{mg} / \mathrm{L}$, while malnutrition was defined as those with serum albumin $<30 \mathrm{~g} / \mathrm{L}$. Serum Angpt- 2 was significantly different across the four groups of patients stratified on the basis of inflammation and malnutrition (overall; $p=0.004$ ). Serum $\log _{10}$ Angpt-2 was the highest among patients with both inflammation and malnutrition and lowest among those without inflammation and malnutrition $(p=0.01)$. No significant difference was noted in serum $\log _{10}$ Angpt-2 between patients with either inflammation or malnutrition $(p>0.05$, Additional file 1: Figure S1B). Finally, patients were stratified into four groups on the basis of the presence of zero, one, two and all three components of the malnutrition, inflammation, atherosclerosis/calcification (MIAC) syndrome. Serum $\log _{10}$ Angpt-2 showed a significant increase across the four groups of patients with increasing components of the MIAC syndrome (overall; $p<0.001$ ). Furthermore, serum $\log _{10}$ sTie-2 and $\log _{10}$ Angpt-1/Angpt-2 ratio were significantly different among four groups (overall; $p=0.001$ and $p=0.007$, respectively). Serum $\log _{10}$ sTie-2 was the highest among patients with all three components of MIAC syndrome, while $\log _{10}$ Angpt-1/Angpt-2 ratio was the lowest among these patients. There was no significant difference of serum $\log _{10}$ Angpt-1 level among four groups (overall; $p=0.5$ ) (Fig. 1). 
Table 2 Clinical characteristics of patients across tertiles of serum Angpt-2

\begin{tabular}{|c|c|c|c|c|}
\hline \multirow[t]{2}{*}{ Variables } & \multicolumn{3}{|c|}{ Serum Angpt- 2 in tertiles } & \multirow[t]{2}{*}{$p$ for trend } \\
\hline & Lower $(n=108)$ & Middle $(n=108)$ & Upper $(n=108)$ & \\
\hline Age (year) & $55.2 \pm 14.5$ & $57.8 \pm 13.5$ & $59.3 \pm 14.1$ & 0.1 \\
\hline Male gender (n [\%]) & $56(52 \%)$ & $56(52 \%)$ & $54(50 \%)$ & 0.9 \\
\hline Dialysis duration (mo) & $25.6(3.2-55.1)$ & $34.9(12.6-60.7)$ & $34.6(15.1-55.8)$ & 0.3 \\
\hline Diabetes mellitus (n [\%]) & $22(20.4 \%)$ & $28(25.9 \%)$ & $34(31.5 \%)$ & 0.2 \\
\hline Body mass index $\left(\mathrm{kg} / \mathrm{m}^{2}\right)$ & $22.1 \pm 3.8$ & $23.2 \pm 3.7$ & $24.3 \pm 4.1$ & $<0.001$ \\
\hline Background AVD (n [\%]) & $26(24.1 \%)$ & $34(31.5 \%)$ & $39(36.1 \%)$ & 0.2 \\
\hline Background VC (n [\%]) & $17(15.7 \%)$ & $22(20.4 \%)$ & $28(25.9 \%)$ & 0.2 \\
\hline Hemoglobin (g/L) & $107.7 \pm 15.7$ & $107.7 \pm 16.8$ & $106.7 \pm 18.6$ & 0.9 \\
\hline Serum albumin (g/L) & $37.0 \pm 4.6$ & $37.0 \pm 4.5$ & $37.1 \pm 4.8$ & 0.9 \\
\hline$n P C R$ & $0.93 \pm 0.19$ & $0.87 \pm 0.19$ & $0.83 \pm 0.15$ & $<0.001$ \\
\hline $\mathrm{Ca} \times \mathrm{P}\left(\mathrm{mg}^{2} / \mathrm{dL}^{2}\right)$ & $54 \pm 17$ & $58 \pm 17$ & $62 \pm 22$ & 0.009 \\
\hline iPTH (pg/L) & 269 (124.9-568.0) & $266.0(133.3-563.5)$ & $376(149.8-616.3)$ & 0.3 \\
\hline hs-CRP (mg/L) & $1.37(0.65-3.73)$ & $2.63(0.89-5.72)$ & $3.7(1.45-8.38)$ & $<0.001$ \\
\hline $\mathrm{BNP}(\mathrm{pg} / \mathrm{mL})$ & $66.5(23.0-158.8)$ & $89(50.5-202.8)$ & $97.5(44.0-198.8)$ & 0.006 \\
\hline Total cholesterol (mmol/L) & $4.77(4.05-5.40)$ & $5.05(4.25-5.69)$ & $4.64(3.97-5.50)$ & 0.08 \\
\hline LDL cholesterol (mmol/L) & $2.68(2.14-3.26)$ & $2.85(2.24-3.40)$ & $2.56(1.83-3.07)$ & 0.03 \\
\hline HDL cholesterol (mmol/L) & $1.17(0.92-1.58)$ & $1.16(0.93-1.50)$ & $1.10(0.86-1.31)$ & 0.07 \\
\hline Triglyceride (mmol/L) & $1.50(1.13-2.24)$ & $1.67(1.17-2.46)$ & $1.85(1.22-3.03)$ & 0.08 \\
\hline LV mass index $\left(\mathrm{g} / \mathrm{m}^{2}\right)$ & $114.9(82.2-159.4)$ & $128.3(91.8-177.5)$ & 136.0 (92.9-189.8) & 0.2 \\
\hline LV ejection fraction (\%) & $67(64-71)$ & $65.5(60-69.8)$ & $64(58-68.5)$ & 0.005 \\
\hline Total weekly urine clearance & $2.05 \pm 0.41$ & $1.91 \pm 0.36$ & $1.86 \pm 0.30$ & 0.001 \\
\hline $\begin{array}{l}\text { Total weekly creatinine clearance }(\mathrm{L} / \\
\left.\mathrm{wK} / 1.73 \mathrm{~m}^{2}\right)\end{array}$ & $67.68 \pm 21.42$ & $61.47 \pm 17.40$ & $56.88 \pm 13.61$ & $<0.001$ \\
\hline Residual renal function (mL/min) & $1.96(0.53-4.18)$ & $0.77(0-2.52)$ & $0.21(0-1.88)$ & $<0.001$ \\
\hline
\end{tabular}

Calcium $\times$ phosphorus product in $\mathrm{mg}^{2} / \mathrm{dL}^{2}$ to $\mathrm{mmol}^{2} / \mathrm{L}^{2}, \times 0.0806$

$A V D$ atherosclerotic vascular disease, VC valvular calcification, Angpt-2 angiopoietin-2, $n P C R$ normalized protein catabolic rate, $h s$ - $C R P$ high sensitive $C$-reactive protein, $C a \times P$ calcium $\times$ phosphorus product, $B N P$ brain natriuretic peptide, $L V$ left ventricular, $i P T H$ intact parathyroid hormone, $L D L$ lower-density lipoprotein, $H D L$ highdensity lipoprotein

\section{Circulating angiopoietin-2 level and patients' outcomes}

After follow-up for $31.7 \pm 13.5$ months, 77 patients (24\%) had died and 28 patients (9\%) had undergone kidney transplantation, 31 patients (10\%) were switched to permanent hemodialysis therapy, 9 patients $(3 \%)$ had transferred to other centers and 2 patients $(0.6 \%)$ had out of follow-up (Both of them were out of touch). Causes of death included 9 acute myocardial ischemic events, 20 strokes, 10 sudden deaths, 3 heart failure episodes, 5 peripheral vascular diseases, 6 peritonitis episodes, 12 other infections, 4 malignancies (1 lung carcinoma, 1 breast carcinoma and 2 stomach carcinoma) and 8 patients with etiology unknown. Baseline median serum Angpt-2 level was significantly higher in patients who died versus those who survived during follow-up [6.58 (4.36-9.28) ng/mL versus 5.06 (3.33-7.51) ng/mL, respectively; $p=0.002$ ].

Fifty-seven patients experienced one or more cardiovascular events. The first cardiovascular event included 27 strokes, 13 acute myocardial ischemic events, 7 peripheral vascular disease events and 10 sudden cardiac deaths. Baseline median serum Angpt-2 level was significantly higher in patients who had one or more cardiovascular events versus those with no cardiovascular event during follow-up [6.63 (5.05-6.78) $\mathrm{ng} / \mathrm{mL}$ versus 5.08 (3.32-7.59) ng/mL, $p<0.001]$.

According to the Kaplan-meier survival analysis, a significant increase in cardiovascular mortality (log rank $=7.51, p=0.023$; Fig. $2 \mathrm{~b}$ ), and fatal or nonfatal cardiovascular event ( $\log \operatorname{rank}=11.54, p=0.003$; Fig. 2c) was observed across the three tertiles of increasing serum Angpt-2. While there was no significant difference of allcause mortality among three tertiles of serum Angpt-2 ( $\log$ rank $=4.19, p=0.1$; Fig. 2a). By univariate Cox analysis, serum Angpt-2 showed a highly significant association with all-cause mortality $(p=0.007)$ as well as fatal and non-fatal cardiovascular events $(p=0.001$, Table 3$)$.

In the multivariate Cox regression analysis, the significance of serum Angpt-2 associated with all-cause mortality in model was lost when adjusting for age, male gender, 


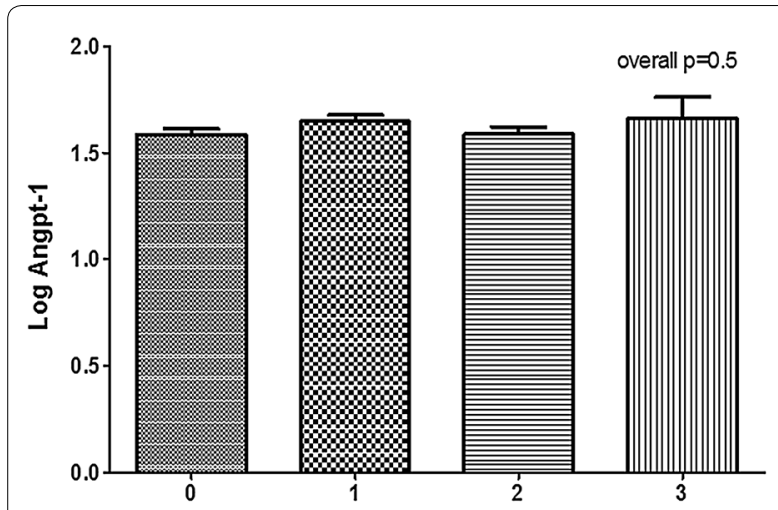

Components of the Malnutrition, Inflammation, Atherosclerosis/Calcification syndrome

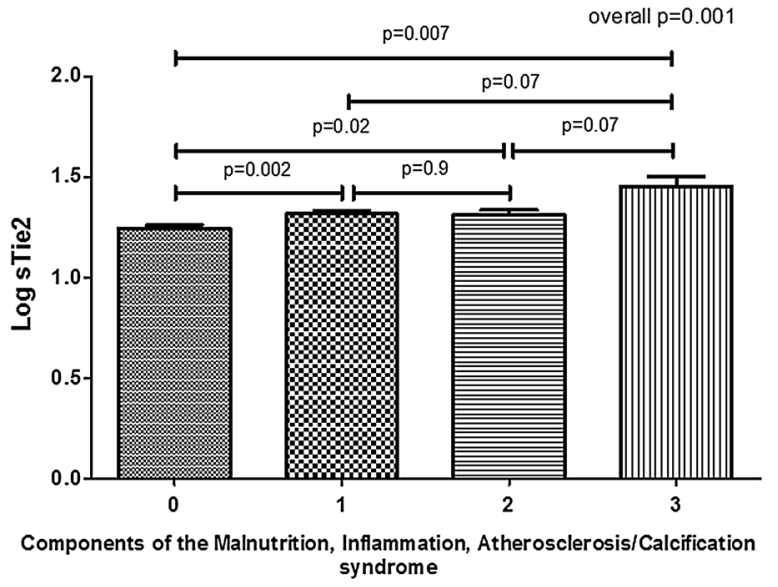

Fig. 1 Serum Angpt-1, Angpt-2, sTie-2 concentration and Angpt-1/Angpt-2 ratio in relation to the presence of zero $(n=138)$, one $(n=118)$, two $(n=62)$ and all three $(n=6)$ components of the malnutrition, inflammation, atherosclerosis/calcification syndrome. Malnutrition was defined as serum albumin $<30 \mathrm{~g} / \mathrm{L}$, inflammation was defined as $\mathrm{hs}-\mathrm{CRP} \geq 5 \mathrm{mg} / \mathrm{L}$, atherosclerosis/calcification was defined by the presence of background AVD or cardiac VC

diabetes and components of MIAC syndrome (hs-CRP, serum albumin, background VC and background AVD) $(p=0.3$, Table 4). Otherwise, in the multivariate Cox regression models for fatal and non-fatal cardiovascular events, serum Angpt-2 remained an independently predictive factor when adjusting for age, male gender, diabetes, LDL cholesterol, LVMI and components of MIAC syndrome (hs-CRP, serum albumin, background VC and background AVD) $(p=0.02$, Table 5$)$.

\section{Discussion}

To our knowledge, this is the first prospective study investigating the correlation of circulating angiopoietin-2 with the MIAC syndrome, as well as the impact of Angpt-2 in predicting clinical outcomes of patients undergoing PD. We find that: (i) serum Angpt-2 levels closely link with MIAC syndrome in PD patients. (ii) high Angpt-2 levels independently predict fatal and non-fatal cardiovascular events in PD patients.

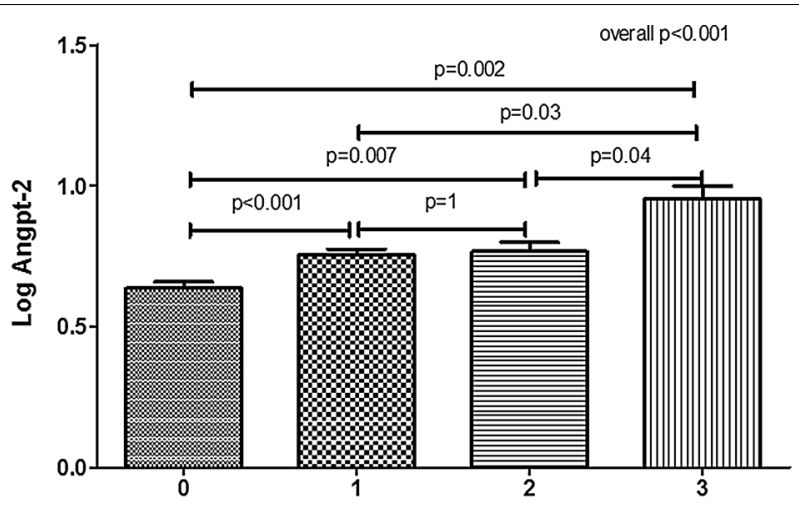

Components of the Malnutrition, Inflammation, Atherosclerosis/Calcification syndrome

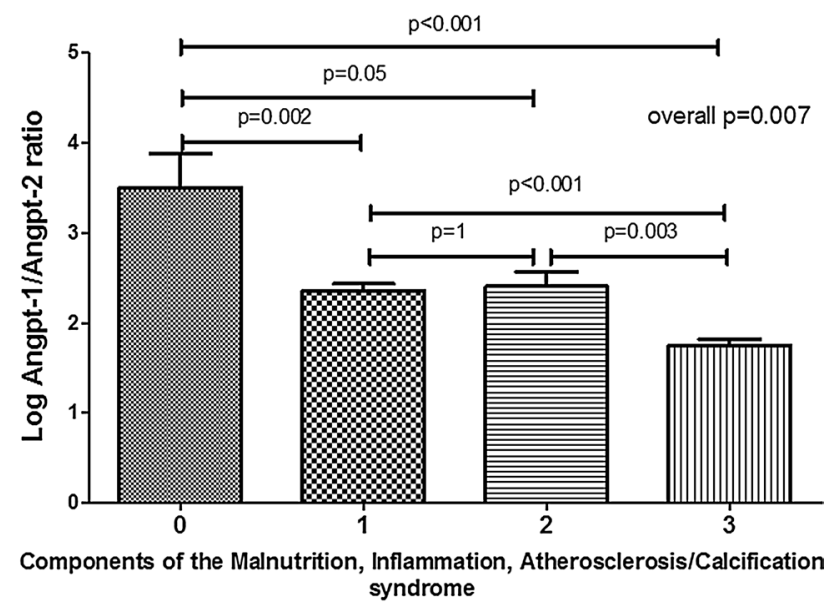

Although Angpt-1 is constitutively expressed throughout adult vessels providing a stabilization signal, Angpt-2 expression is observed only at sites of active vascular remodeling and neoangiogenesis [31]. We found that the serum Angpt-2 levels were comparable among Chinese PD patients with the study by David et al. [19] in PD patients, which was significantly higher than controls. It has been identified that endothelial Weibel-Palade bodies (WPBs) is the primary source of Angpt-2, which is dramatically up-regulated on endothelial cell activation, frequently observed in patients with CKD [32, 33]. In addition, it has been reported that nitric oxide has decreased availability in patients with CKD, which is known as important inhibitor of WPB exocytosis [34]. We hypothesize that the increased serum Angpt-2 levels we found in our patients might be caused by excess WPB exocytosis as a consequence of decrease nitric oxide production. Furthermore, in vitro, increased Angpt- 2 expression has been observed on stimulation with high glucose 


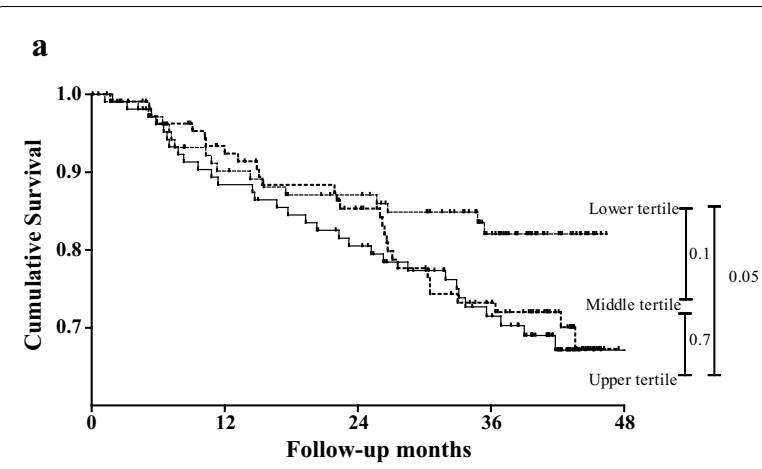

All-Cause Mortality (Log rank=4.19, $\mathrm{p}=0.1$ )

b

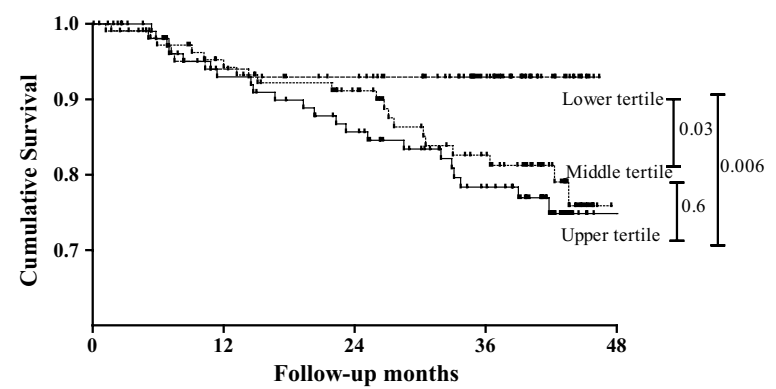

Cardiovascular Mortality $(\log$ rank $=7.51, \mathrm{p}=0.023)$

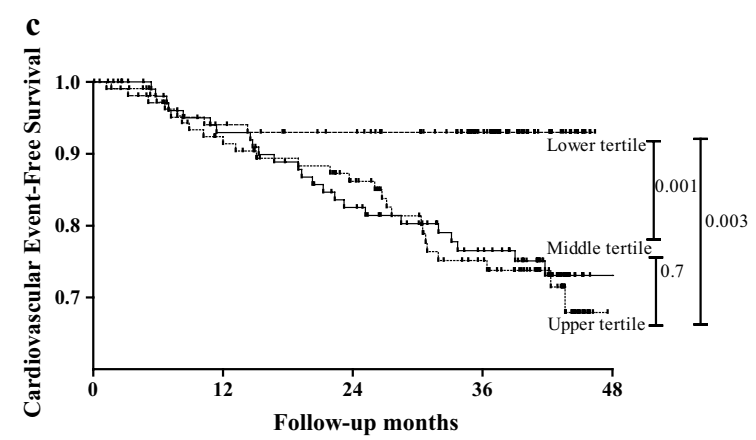

Cardiovascular event-free survival (Log rank=11.54, $\mathrm{p}=0.003$ )

Fig. 2 Kaplan-Meier estimates of a overall survival probability and $\mathbf{b}$ cardiovascular mortality $\mathbf{c}$ fatal or nonfatal cardiovascular event-free survival probability of patients stratified by tertiles of serum angiopoietin-2 (Angpt-2). Lower tertile: Angpt-2 $\leq 3.94$ ng/ $\mathrm{mL}$; middle tertile: Angpt-2 $>3.94$ to $<7.03 \mathrm{ng} / \mathrm{mL}$; upper tertile Angpt-2 $\geq 7.03 \mathrm{ng} / \mathrm{mL}$

and tumor necrosis factor-alpha (TNF- $\alpha$ ) levels, both frequently observed in dialysis patients [16, 20]. Further study was needed to explore the underlying mechanism.

In present study, patients in the upper tertile of serum Angpt-2 not only had the highest CRP but also were the most malnourished. This suggests that Angpt- 2 not only is a potent factor involving in angiogenesis as shown previously [13-15], but may also be useful in indentifying PD patients complicated with MIAC syndrome. It has been reported that circulating Angpt-2 is significantly correlated with CRP level in CKD patients and elevated Angpt-2 levels are strong predictors of long-term mortality in these patients [35]. In a dose-dependent manner, Angpt-2 competitively inhibits binding of Angpt- 1 to Tie2 , followed by loss of vessel integrity, vascular leakage and induction of inflammatory gene expression [17]. The proinflammatory property of Angpt-2 was evidenced further by increasing expression of Angpt- 2 by the TNF- $\alpha$ treatment and knockdown of Angpt- 2 ameliorating TNF- $\alpha$ induced apoptosis [36]. Even though high Angpt-2 and high CRP may represent the same biological event, our data suggest that Angpt-2 may be useful in further stratifying the severity of the MIAC syndrome in PD patients. In present study, serum Angpt-2 and albumin were not correlated, but patients in the upper tertile of Angpt-2 levels had the lowest level of nPCR, another important index of nutrition statue in PD patients $(p<0.001)$. It has been found that higher plasma Angpt-2 was closely related with severe malnutrition among patients with advances human immunodeficiency virus (HIV) infection [37]. The causal relationship between malnutrition and circulating Angpt-2 levels need further study.

Emerging data support the notion that circulating angiopoietins levels closely related with atherosclerotic diseases. Previous studies had found that circulating Angpt-2 levels were related with atherosclerosis as well as the degree of myocardial damage [38, 39]. In addition, high Angpt-2 and low Angpt-1 levels were positively associated with abnormal cardiac structure in stage 3-5 CKD patients [40] and circulating Angpt-2 was inversely related to glomerular filtration rate (GFR) and increased with advanced CKD [18]. It has been reported that Angpt-2 level is an indicator of vascular bed-specific atherosclerotic burden in dialysis patients, having correlation with degree of both coronary heart disease (CHD) and peripheral arterial disease (PAD) [19]. Furthermore, a study in children on chronic dialysis has found that serum Angpt-2 positively correlated with dialysis duration, as well as with an anti-angiogenic (high soluble vascular endothelial growth factor receptor-1 and low vascular endothelial growth factor-A) and pro-inflammatory (high urate, E-selectin, P-selectin and vascular cell adhesion molecule-1) milieu [21]. This is well in line with our findings that patients having all components of the MIAC syndrome had the highest serum Angpt-2. Those findings gave additional evidence that serum Angpt-2 might be an important biomarker of atherosclerotic diseases as well as vascular calcification, which might dependent on its role in inducing micro-inflammation.

In present study, we found that serum Angpt-2 was an independently predictive factor for fatal and non-fatal cardiovascular events when adjusting for components of 
Table 3 Univariate Cox analysis of factors in relation to all-cause mortality and cardiovascular events

\begin{tabular}{|c|c|c|c|c|c|}
\hline & \multirow[t]{2}{*}{ Unite increase } & \multicolumn{2}{|c|}{ All-cause mortality $(n=77)$} & \multicolumn{2}{|c|}{$\begin{array}{l}\text { Fatal and non-fatal cardiovascular events } \\
(n=57)\end{array}$} \\
\hline & & HR (95\%) & $p$ value & HR (95\%) & $p$ value \\
\hline Age & 1 year & $1.06(1.04-1.08)$ & $<0.001$ & $1.04(1.02-1.07)$ & $<0.001$ \\
\hline Male gender & - & $0.94(0.60-1.46)$ & 0.8 & $0.88(0.53-1.48)$ & 0.6 \\
\hline Diabetes mellitus & - & $2.39(1.52-3.77)$ & $<0.001$ & $2.29(1.35-3.89)$ & 0.002 \\
\hline Hypertension & - & $4.75(0.66-34.18)$ & 0.1 & $3.52(0.49-25.46)$ & 0.2 \\
\hline Background AVD & - & $4.94(3.10-7.88)$ & $<0.001$ & $4.59(2.69-7.85)$ & $<0.001$ \\
\hline Background VC & - & $2.02(1.25-3.26)$ & 0.004 & $1.33(0.73-2.41)$ & 0.3 \\
\hline $\mathrm{Ca} \times \mathrm{P}$ & $1 \mathrm{mg}^{2} / \mathrm{dL}^{2}$ & $1.0(0.98-1.01)$ & 0.4 & $1.0(0.98-1.01)$ & 0.6 \\
\hline iPTH & $1 \mathrm{pmol} / \mathrm{L}$ & $1.0(0.99-1.0)$ & 0.4 & $0.99(0.99-1)$ & 0.2 \\
\hline hs-CRP & $1 \mathrm{mg} / \mathrm{L}$ & $1.02(1.0-1.03)$ & 0.03 & $1.01(0.99-1.03)$ & 0.2 \\
\hline Serum albumin & $1 \mathrm{~g} / \mathrm{L}$ & $0.91(0.86-0.95)$ & $<0.001$ & $0.91(0.89-0.97)$ & 0.001 \\
\hline Hemoglobin & $1 \mathrm{~g} / \mathrm{L}$ & $1.0(0.98-1.01)$ & 0.7 & $1.00(0.99-1.02)$ & 0.8 \\
\hline LDL cholesterol & $1 \mathrm{mmol} / \mathrm{L}$ & $1.19(0.99-1.44)$ & 0.06 & $1.31(1.09-1.57)$ & 0.004 \\
\hline LV mass index & $1 \mathrm{~g} / \mathrm{m}^{2}$ & $1.002(0.99-1.01)$ & 0.2 & $1.004(1.0-1.008)$ & 0.05 \\
\hline $\log _{10}$ Angpt-2 & $1 \mathrm{ng} / \mathrm{mL}$ & $3.67(1.43-9.45)$ & 0.007 & $6.71(2.15-20.88)$ & 0.001 \\
\hline Residual renal function & $1 \mathrm{~mL} / \mathrm{min}$ & $0.93(0.83-1.04)$ & 0.2 & $0.97(0.86-1.10)$ & 0.7 \\
\hline
\end{tabular}

Calcium $\times$ phosphorus product in $\mathrm{mg}^{2} / \mathrm{dL}^{2}$ to $\mathrm{mmol}^{2} / \mathrm{L}^{2}, \times 0.0806$

$A V D$ atherosclerotic vascular disease, $V C$ valvular calcification, $C a \times P$ calcium $\times$ phosphorus product, iPTH intact parathyroid hormone, $h s-C R P$ high sensitive $C$-reactive protein, LDL lower-density lipoprotein, LV left ventricular, Angpt-2 angiopoietin-2

Table 4 Multivariate Cox regression models for all-cause mortality [expressed as hazard ratios ( $95 \%$ confidence intervals), $p$-value]

\begin{tabular}{lllc}
\hline & Unit increase & HR (95\%) & p value \\
\hline Age & 1 year & $1.03(1.01-1.06)$ & 0.006 \\
Male gender & - & $0.86(0.54-1.37)$ & 0.5 \\
Diabetes mellitus & - & $1.28(0.78-2.10)$ & 0.3 \\
Log $_{10}$ Angpt-2 & $1 \mathrm{ng} / \mathrm{mL}$ & $1.69(0.64-4.47)$ & 0.3 \\
hs-CRP & $1 \mathrm{mg} / \mathrm{L}$ & $1.01(0.99-1.03)$ & 0.4 \\
Serum albumin & $1 \mathrm{~g} / \mathrm{L}$ & $0.93(0.88-0.99)$ & 0.02 \\
Background VC & - & $1.05(0.61-1.80)$ & 0.9 \\
Background AVD & - & $2.93(1.76-4.88)$ & $<0.001$ \\
\hline
\end{tabular}

$A V D$ atherosclerotic vascular disease, VC valvular calcification, $h s-C R P$ high sensitive C-reactive protein, Angpt-2 angiopoietin-2

MIAC syndrome and other parameters. A communitybased study including 3220 participants had showed that increasing serum Angpt-2 concentrations were associated with higher risk for all-cause and cardiovascular mortality [41]. A recent report also linked outcome in CKD stages 3-5 patients to circulating serum Angpt-2 and found that baseline Angpt-2 levels was an independent predictor for major adverse cardiovascular events (MACE) as well as all-cause mortality [42]. As shown in our study, serum Angpt-2, being a biomarker of calcification and micro-inflammation, was indeed closely related to the MIAC syndrome. Previous study has found that
Table 5 Multivariate Cox regression models for ftal and non-fatal cardiovascular events [expressed as hazard ratios ( $95 \%$ confidence intervals), $p$-value]

\begin{tabular}{llll}
\hline & Unit increase & HR (95\%) & $\boldsymbol{p}$ value \\
\hline Age & 1 year & $1.03(0.99-1.06)$ & 0.07 \\
Male gender & - & $0.52(0.25-1.08)$ & 0.08 \\
Diabetes mellitus & - & $1.11(0.59-2.09)$ & 0.7 \\
LDL cholesterol & $1 \mathrm{mmol} / \mathrm{L}$ & $1.06(0.78-1.45)$ & 0.7 \\
LV mass index & $1 \mathrm{~g} / \mathrm{m}^{2}$ & $1.01(1.00-1.01)$ & 0.04 \\
Log $_{10}$ Angpt-2 & $1 \mathrm{ng} / \mathrm{mL}$ & $4.53(1.24-16.47)$ & 0.02 \\
hs- CRP & $1 \mathrm{mg} / \mathrm{L}$ & $1.00(0.97-1.03)$ & 0.9 \\
Serum albumin & $1 \mathrm{~g} / \mathrm{L}$ & $0.97(0.90-1.05)$ & 0.4 \\
Background VC & - & $0.52(0.24-1.13)$ & 0.1 \\
Background AVD & - & $3.11(1.60-6.05)$ & 0.001 \\
\hline
\end{tabular}

$A V D$ atherosclerotic vascular disease, $V C$ valvular calcification, $h s-C R P$ high sensitive C-reactive protein, $L D L$ lower-density lipoprotein, $L V$ left ventricular, Angpt-2 angiopoietin-2

MIAC syndrome strongly predicted all-cause mortality and cardiovascular deaths in PD patients [43]. Besides, a study among patients with type I diabetes had also found that Angpt-2 was a significant independent factor for atherosclerosis risk due to its role in vascular dysfunction and may enable the recognition of preclinical cardiac impairment [44]. Furthermore, circulating Angpt-2 was also a biomarker for heart failure in adults with congenital heart disease (ACHD), which was comparable to NT-proBNP [45]. The levels of Angpt-2 and sTie-2 were 
associated with the metabolic syndrome (MetS) [46]. Increasing circulating Angpt-2 levels was an independent predictor for fatal or non-fatal cardiovascular events in PD patients partly due to its close relationship with MIAC syndrome, and partly due to its role in endothelial activation. As endothelial cells are involved in many aspects of vascular biology, including barrier function, immune surveillance, blood clotting, and atherosclerosis, ongoing endothelial activation as manifested by persistent elevations in plasma Angpt-2 may predispose to a wide array of adverse outcomes. Whether it has causal relationship with mortality, especially the cardiovascular event in PD patients, requires further investigation.

Our study had several limitations that require consideration. Firstly, a single time point measurement of serum Angpt-2 was performed and may not reflect changes over time or time-averaged exposure. Secondly, the cross-sectional relationship observed between serum Angpt-2 and the components of MIAC syndrome, however strong, did not allow causal inferences and the relationship could be incidental. Thirdly, the inclusion of prevalent but not incident PD patients may introduce survival bias.

\section{Conclusions}

In summary, our study shows a close association between serum Angpt-2 and cardiac valvular calcification, atherosclerosis, inflammation and malnutrition in PD patients. High circulating Angpt-2 levels is an independently predictive factor for fatal and non-fatal cardiovascular events in PD patients. Further study is needed to explore a possible mechanistic link between Angpt-2 and MIAC syndrome as well as cardiovascular events in patients undergoing PD treatment.

\section{Additional file}

Additional file 1: Figure S1. (A) Serum Angpt-2 concentration in relation to presence or absence of valvular calcification (VC) and atheroscleroticvascular disease (AVD). (B) Serum Angpt-2 concentration in relation to the presence (I+ ve: $C R P \geq 5 \mathrm{mg} / \mathrm{L}$ ) or absence (l-ve: $C R P<5 \mathrm{mg} / \mathrm{L})$ of inflammation and presence $(M+$ ve: albumin $<30 \mathrm{~g} / \mathrm{L})$ or absence $(M+$ ve: albumin $\geq 30 \mathrm{~g} / \mathrm{L}$ ) of malnutrition.

\section{Abbreviations}

Angpt-2: angiopoietin-2; MIAC: malnutrition, inflammation, atherosclerosis and cardiac valvular calcification; PD: peritoneal dialysis; hs-CRP: high sensitive C-reactive protein; $\mathrm{nPCR}$ : normalized protein catabolic rate; BNP: brain natriuretic peptide; LDL: lower-density lipoprotein; LV: left ventricular; ESRD: end-stage renal disease; CVD: cardiovascular diseases; CRP: C-reactive protein; IL-6: interleukin-6; SGA: subjective global assessment; MIA: malnutrition, inflammation and atherosclerosis; VC: valvular calcification; Angpt-1: angiopoietin-1; CKD: chronic kidney diseases; DM: diabetes mellitus; AVD: atherosclerotic vascular disease; sTie-2: soluble Tie-2; ELISA: enzyme linked immunosorbent assay; iPTH: intact parathyroid hormone; HDL: high-density lipoprotein; ANOVA: one-way analysis of variance; WPBs: Weibel-Palade bodies; TNF-a: tumor necrosis factor-alpha; HIV: human immunodeficiency virus; GFR: glomerular filtration rate; CHD: coronary heart disease; PAD: peripheral arterial disease; MACE: major adverse cardiovascular events; ACHD: adults with congenital heart disease; NT-proBNP: N-terminal pro-B-type natriuretic peptide; MetS: metabolic syndrome; Ca $\times$ P: calcium $\times$ phosphorus product.

\section{Authors' contributions}

XY participated in the design of the study and performed the statistical analysis. WF conceived of the study, and participated in its design and coordination and helped to draft the manuscript. $\mathrm{HZ}, \mathrm{ZZ}$ and $\mathrm{HY}$ participated in clinical data collection. YS carried out the enzyme linked immunosorbent assay. ZN and $J Q$ helped to draft the manuscript. All authors read and approved the final manuscript.

\section{Author details}

${ }^{1}$ Department of Nephrology, Renji Hospital, School of Medicine, Shanghai Jiao Tong University, No. 160, Pujian Road, Pudong District, Shanghai 200127, People's Republic of China. ${ }^{2}$ Shanghai Center for Peritoneal Dialysis Research, Shanghai, People's Republic of China.

\section{Acknowledgements}

We thank all of the doctors at the Nephrology Department of Renji Hospital in Shanghai, China for their work.

\section{Competing interests}

The authors declare that they have no competing interests.

\section{Availability of data and materials}

Please contact author for data requests.

\section{Consent for publication}

All participants gave their written informed consent.

\section{Ethics approval and consent to participate}

The study protocol was approved by the Human Research Ethics Committee of Renji Hospital, School of Medicine, Shanghai Jiao Tong University.

\section{Funding}

This work was supported by the National Nature Science Foundation Grant of China (81370864, 81670691), Shanghai Municipal Education CommissionGaofeng Clinical Medicine Grant (20152211) and Shanghai Pujiang Program (16PJ1405900).

\section{Publisher's Note}

Springer Nature remains neutral with regard to jurisdictional claims in published maps and institutional affiliations.

Received: 14 August 2018 Accepted: 9 November 2018 Published online: 16 November 2018

\section{References}

1. United States Renal Data System. 2017 USRDS annual data report: epidemiology of kidney disease in the United States. National Institutes of Health, National Institute of Diabetes and Digestive and Kidney Diseases, Bethesda, MD, 2017.

2. Kim SB, Min WK, Lee SK, Park JS, Hong CD, Yang WS. Persistent elevation of $\mathrm{C}$-reactive protein and ischemic heart disease in patients with continuous ambulatory peritoneal dialysis. Am J Kidney Dis. 2002;39:342-6.

3. Wang AY, Woo J, Lam CW, Wang M, Sea MM, Lui SF, Li PK, Sanderson J. Is a single time point C-reactive protein predictive of outcome in peritoneal dialysis patients? J Am Soc Nephrol. 2003;14:1871-9.

4. Honda H, Qureshi AR, Heimburger O, Barany P, Wang K, Pecoits-Filho R, Stenvinkel $P$, Lindholm B. Serum albumin, C-reactive protein, interleukin 6, and fetuin a as predictors of malnutrition, cardiovascular disease, and mortality in patients with ESRD. Am J Kidney Dis. 2006;47:139-48. 
5. Lambie M, Chess J, Donovan KL, Kim YL, Do JY, Lee HB, Noh H, Williams PF, Williams AJ, Davison S, Dorval M, Summers A, Williams JD, Bankart J, Davies SJ, Topley N. Independent effects of systemic and peritoneal inflammation on peritoneal dialysis survival. J Am Soc Nephrol. 2013;24:2071-80

6. Chung SH, Lindholm B, Lee HB. Is malnutrition an independent predictor of mortality in peritoneal dialysis patients? Nephrol Dial Transplant. 2003;18:2134-40.

7. Kaysen GA. Biological basis of hypoalbuminemia in ESRD. J Am Soc Nephrol. 1998;9:2368-76

8. Stenvinkel P, Heimburger O, Paultre F, Diczfalusy U, Wang T, Berglund $L$, Jogestrand T. Strong association between malnutrition, inflammation, and atherosclerosis in chronic renal failure. Kidney Int. 1999;55:1899-911.

9. Tonbul HZ, Demir M, Altintepe L, Guney I, Yeter E, Turk S, Yeksan M, Yildiz A. Malnutrition-inflammation-atherosclerosis (MIA) syndrome components in hemodialysis and peritoneal dialysis patients. Ren Fail. 2006;28:287-94

10. Goodman WG, Goldin J, Kuizon BD, Yoon C, Gales B, Sider D, Wang Y, Chung J, Emerick A, Greaser L, Elashoff RM, Salusky IB. Coronary-artery calcification in young adults with end-stage renal disease who are undergoing dialysis. N Engl J Med. 2000;342:1478-83.

11. Wang AY, Wang M, Woo J, Lam CW, Li PK, Lui SF, Sanderson JE. Cardiac valve calcification as an important predictor for all-cause mortality and cardiovascular mortality in long-term peritoneal dialysis patients: a prospective study. J Am Soc Nephrol. 2003;14:159-68.

12. Wang AY, Woo J, Wang M, Sea MM, Ip R, Li PK, Lui SF, Sanderson JE. Association of inflammation and malnutrition with cardiac valve calcification in continuous ambulatory peritoneal dialysis patients. J Am Soc Nephrol. 2001;12:1927-36.

13. Gale NW, Yancopoulos GD. Growth factors acting via endothelial cellspecific receptor tyrosine kinases: VEGFs, angiopoietins, and ephrins in vascular development. Genes Dev. 1999:13:1055-66.

14. Felcht M, Luck R, Schering A, Seidel P, Srivastava K, Hu J, Bartol A, Kienast Y, Vettel C, Loos EK, Kutschera S, Bartels S, Appak S, Besemfelder E, Terhardt D, Chavakis E, Wieland T, Klein C, Thomas M, Uemura A, Goerdt S, Augustin HG. Angiopoietin-2 differentially regulates angiogenesis through TIE2 and integrin signaling. J Clin Invest. 2012;122:1991-2005.

15. Jeansson M, Gawlik A, Anderson G, Li C, Kerjaschki D, Henkelman M, Quaggin SE. Angiopoietin-1 is essential in mouse vasculature during development and in response to injury. J Clin Invest. 2011;121:2278-89.

16. Fiedler U, Reiss Y, Scharpfenecker M, Grunow V, Koidl S, Thurston G, Gale NW, Witzenrath M, Rosseau S, Suttorp N, Sobke A, Herrmann M, Preissner KT, Vajkoczy P, Augustin HG. Angiopoietin-2 sensitizes endothelial cells to TNF-alpha and has a crucial role in the induction of inflammation. Nat Med. 2006;12:235-9.

17. Fiedler $\mathrm{U}$, Augustin $\mathrm{HG}$. Angiopoietins: a link between angiogenesis and inflammation. Trends Immunol. 2006;27:552-8.

18. David S, Kumpers P, Lukasz A, Fliser D, Martens-Lobenhoffer J, BodeBoger SM, Kliem V, Haller H, Kielstein JT. Circulating angiopoietin-2 levels increase with progress of chronic kidney disease. Nephrol Dial Transplant. 2010;25:2571-6.

19. David S, Kumpers $\mathrm{P}$, Hellpap J, Horn R, Leitolf H, Haller H, Kielstein JT. Angiopoietin 2 and cardiovascular disease in dialysis and kidney transplantation. Am J Kidney Dis. 2009:53:770-8.

20. Yao D, Taguchi T, Matsumura T, Pestell R, Edelstein D, Giardino I, Suske G, Rabbani N, Thornalley PJ, Sarthy VP, Hammes HP, Brownlee M. High glucose increases angiopoietin-2 transcription in microvascular endothelial cells through methylglyoxal modification of mSin3A. J Biol Chem. 2007;282:31038-45.

21. Shroff RC, Price KL, Kolatsi-Joannou M, Todd AF, Wells D, Deanfield J, Johnson RJ, Rees L, Woolf AS, Long DA. Circulating angiopoietin-2 is a marker for early cardiovascular disease in children on chronic dialysis. PLOS ONE. 2013:8:e56273.

22. Nolph KD, Moore HL, Twardowski ZJ, Khanna R, Prowant B, Meyer M, Ponferrada L. Cross-sectional assessment of weekly urea and creatinine clearances in patients on continuous ambulatory peritoneal dialysis. ASAIO J. 1992;38:M139-42.

23. van Olden RW, Krediet RT, Struijk DG, Arisz L. Measurement of residual renal function in patients treated with continuous ambulatory peritoneal dialysis. J Am Soc Nephrol. 1996;7:745-50.
24. Randerson DH, Chapman GV, Farrell PC. In: Atkins RC, Farrell PC, Thomson $\mathrm{N}$, editors. Amino acid and dietary status in CAPD patients, peritoneal dialysis. Edinburgh: Churchill-Livingstone; 1981. p. 180-91.

25. Watson PE, Watson ID, Batt RD. Total body water volumes for adult males and females estimated from simple anthropometric measurements. Am J Clin Nutr. 1980;33:27-39.

26. Schiller NB, Shah PM, Crawford M, DeMaria A, Devereux R, Feigenbaum H, Gutgesell H, Reichek N, Sahn D, Schnittger I. Recommendations for quantitation of the left ventricle by two-dimensional echocardiography. American society of echocardiography committee on standards, subcommittee on quantitation of two-dimensional echocardiograms. J Am Soc Echocardiogr. 1989;2:358-67.

27. Wong M, Tei C, Shah PM. Sensitivity and specificity of two-dimensional echocardiography in the detection of valvular calcification. Chest. 1983;84:423-7.

28. Devereux RB, Alonso DR, Lutas EM, Gottlieb GJ, Campo E, Sachs I, Reichek $\mathrm{N}$. Echocardiographic assessment of left ventricular hypertrophy: comparison to necropsy findings. Am J Cardiol. 1986;57:450-8.

29. Engelstein ED, Zipes DP. Sudden cardiac death. In: Alexander RW, Schlant RC, Fuster V, editors. The heart, arteries and veins. NewYork: McGraw-Hill; 1998. p. 1081-112.

30. Myerburg RJ, Castellanos A. Cardiac arrest and sudden death. In: Braunwald $E$, editor. Heart disease: a textbook of cardiovascular medicine. Philadelphia: WB Saunders; 1997. p. 742-79.

31. Maisonpierre PC, Suri C, Jones PF, Bartunkova S, Wiegand SJ, Radziejewski C, Compton D, McClain J, Aldrich TH, Papadopoulos N, Daly TJ, Davis S, Sato TN, Yancopoulos GD. Angiopoietin-2, a natural antagonist for Tie2 that disrupts in vivo angiogenesis. Science. 1997;277:55-60.

32. Weibel ER, Palade GE. New cytoplasmic components in arterial endothelia. J Cell Biol. 1964;23:101-12.

33. Fiedler U, Scharpfenecker M, Koidl S, Hegen A, Grunow V, Schmidt JM, Kriz W, Thurston G, Augustin HG. The Tie-2 ligand angiopoietin-2 is stored in and rapidly released upon stimulation from endothelial cell Weibel-Palade bodies. Blood. 2004;103:4150-6.

34. Schmidt RJ, Baylis C. Total nitric oxide production is low in patients with chronic renal disease. Kidney Int. 2000;58:1261-6.

35. David S, John SG, Jefferies HJ, Sigrist MK, Kumpers P, Kielstein JT, Haller $\mathrm{H}$, McIntyre CW. Angiopoietin-2 levels predict mortality in CKD patients. Nephrol Dial Transplant. 2012;27:1867-72.

36. Sun NN, Li C, Zhou L, Peng Y, Zhang B, Qiu XM, Jiang ZM, Xu J. Lentivirusmediated angiopoietin-2 gene silencing decreases TNF-alpha induced apoptosis of alveolar epithelium cells. Biochem Cell Biol. 2016;94:491-7.

37. Graham SM, Rajwans N, Tapia KA, Jaoko W, Estambale BB, McClelland RS, Overbaugh J, Liles WC. A prospective study of endothelial activation biomarkers, including plasma angiopoietin-1 and angiopoietin-2, in Kenyan women initiating antiretroviral therapy. BMC Infect Dis. 2013;13:263.

38. Lim HS, Lip GY, Blann AD. Angiopoietin-1 and angiopoietin-2 in diabetes mellitus: relationship to VEGF, glycaemic control, endothelial damage/ dysfunction and atherosclerosis. Atherosclerosis. 2005;180:113-8.

39. Lee KW, Lip GY, Blann AD. Plasma angiopoietin-1, angiopoietin-2, angiopoietin receptor tie-2, and vascular endothelial growth factor levels in acute coronary syndromes. Circulation. 2004;1 10:2355-60.

40. Tsai YC, Lee CS, Chiu YW, Kuo HT, Lee SC, Hwang SJ, Kuo MC, Chen HC. Angiopoietin-2, angiopoietin-1 and subclinical cardiovascular disease in chronic kidney disease. Sci Rep. 2016;6:39400.

41. Lorbeer R, Baumeister SE, Dorr M, Nauck M, Grotevendt A, Volzke H, Vasan RS, Wallaschofski H, Lieb W. Circulating angiopoietin-2, its soluble receptor Tie-2, and mortality in the general population. Eur J Heart Fail. 2013;15:1327-34.

42. Tsai YC, Lee CS, Chiu YW, Kuo HT, Lee SC, Hwang SJ, Kuo MC, Chen HC. Angiopoietin-2 as a prognostic biomarker of major adverse cardiovascular events and all-cause mortality in chronic kidney disease. PLoS ONE. 2015;10:e0135181.

43. Wang AY, Woo J, Lam CW, Wang M, Chan IH, Gao P, Lui SF, Li PK, Sanderson JE. Associations of serum fetuin-A with malnutrition, inflammation, atherosclerosis and valvular calcification syndrome and outcome in peritoneal dialysis patients. Nephrol Dial Transplant. 2005;20:1676-85.

44. El-Asrar MA, Elbarbary NS, Ismail EA, Bakr AA. Circulating angiopoietin-2 levels in children and adolescents with type 1 diabetes mellitus: 
relation to carotid and aortic intima-media thickness. Angiogenesis. 2016;19:421-31.

45. Lukasz A, Beutel G, Kumpers P, Denecke A, Westhoff-Bleck M, Schieffer B, Bauersachs J, Kielstein JT, Tutarel O. Angiopoietin-2 in adults with congenital heart disease and heart failure. PLoS ONE. 2013;8:e66861.
46. Lorbeer R, Baumeister SE, Dorr M, Nauck M, Grotevendt A, Schlesinger S, Teumer A, Volzke H, Grabe HJ, Wallaschofski H, Vasan RS, Lieb W. Angiopoietin-2, its soluble receptor Tie-2, and metabolic syndrome components in a population-based sample. Obesity (Silver Spring). 2016;24:2038-41.
Ready to submit your research? Choose BMC and benefit from:

- fast, convenient online submission

- thorough peer review by experienced researchers in your field

- rapid publication on acceptance

- support for research data, including large and complex data types

- gold Open Access which fosters wider collaboration and increased citations

- maximum visibility for your research: over 100M website views per year

At BMC, research is always in progress.

Learn more biomedcentral.com/submissions 